\title{
THE DISCUSSION BETWEEN SPENCER AND WEISMANN.
}

The Inadequacy of 'Natural Selection' : Professor Weismann's Theories: A Rejoinder to Professor Weismann. Herbert SPEnCER. Contemporary Review, Feb., Mar., May, and Dec. I893.

The All-Sufficiency of Natural Selection. A. Weismann. Contemporary Review, Aug. and Sept. I893.

The history of biology during this century will be known in the next as marked by three great discussions relating to evolution. First, that between Cuvier and St. Hilaire, culminating in the famous debate in the French Academy in 1830 , touching the methods of thought which were then leading to the discovery of the law. Second, that of 1858 , caused by the revival of the law itself by Darwin and Wallace, and led by Huxley in England and Haeckel in Germany. Third, the present discussion which began in 1883 , when Weismann first challenged the principle of Inheritance of Acquired Characters as a factor of evolution. This discussion probably culminates in the recent papers under review.

The supreme confidence of both parties is expressed in the titles of these papers-The Inadequacy of 'Natural Selection,' as Spencer's firm conclusion, is faced by The All-Sufficiency of Natural Selection, as Weismann's. The last word on each side is an unwavering confidence in the position originally taken, and a total rejection of the arguments advanced by the opposite side. Spencer's original article seemed so strong that his supporters in England imagined it would be conclusive, yet Weismann certainly gives an equally strong reply, bringing forward as a new and apparently irrefutable argument the case of the evolution of the neuter insects, in which most marvellous adaptations appear, for which the Lamarckian explanation cannot be advanced, because these insects leave no descendants. Yet in Spencer's rejoinder this argument is met in the most clever manner, by the assumption that these adaptations in sexless forms were established in the earlier social states of ants, bees, and wasps before they became sexless and while acquired characters could still be transmitted. In short, this discussion leaves every reader exactly where it finds him, because the honors in logic are evenly divided. Both sides are strong in attack and weak in defence.

While inconclusive it is most stimulating and has attracted wide attention, because the question bears with equal force upon problems of ethics and psychology as upon all lines of biological thought which run in the direction of the life-histories of organisms lower than man. 
To no one is the issue so vital as to these two famous disputants. With Spencer we may say his whole system is at stake, and the permanence of the philosophy to which he has given his life. Weismann has a sudden notoriety to lose and a permanent reputation to gain, because if he is in the right, as the first opponent of the Lamarckian principle of inheritance, and, with Wallace, the champion of the exclusive selection theory of evolution, he will go down to posterity as the greatest biological thinker of this century after Darwin. Now in the issue itself there is no half-way ground; the final result must be the total rout of one side or the other, and under such stress we should find in this discussion the strongest presentation possible of the two positions. This we do not find. It is the purpose of this review, therefore, not to follow arguments, which are so readily accessible and intelligible to all readers, but to show that the position of both Weismann and Spencer is defective-because neither has brought forward inductive evidence.

In fact, the reason these papers, interesting and able as they are, leave no final verdict in the mind is that neither meets the tests of scientific truth. When we look beneath the surface and recover from the first blinding effects of the brilliant style which characterizes both attack and reply, we see that both set forth mainly the modes in which nature may be supposed to act, rather than the mode in which nature does act. Nature, if anything, is illogical in many of her forms.

Weismann's strength lies in his exposure of the weakness of Spencer's position in relation to heredity. His weakness lies in the purely theoretical nature of the support of his own. He brings this charge against himself in the striking passage:

"What is it then that nevertheless makes us believe in this progress as actual, and leads us to ascribe such extraordinary importance to it? Nothing but the power of logic ; * we must assume natural selection to be the principle of explanation of the metamorphoses, because all other apparent principles of explanation fail us, and it is inconceivable that there could be yet another capable of explaining the adaptations of organisms, without assuming the help of a principle of design. In other words, it is the only conceivable natural explanation of organisms regarded as adaptations to conditions."

Have thirty-five years of research under the stimulus of the selection hypothesis failed to bring forth a single fact or group of facts which Weismann, as one of the best informed of all living naturalists, can cite? He could have made no stronger array of evidence against his cause than his dependence throughout these essays upon theoretical considerations in support of his position that the selection principle acts upon any aind every minute shade of character in the organism.

* Italics are our own. 
In the absence of fact, he presents the group of speculations which have grown up in the Neo-Darwinian school, namely : the refinement and apotheosis of selection; the utility or adaptiveness of, and intense premium upon, every variation; selection as a sustaining power; the cessation of selection or panmixia, and finally the reversal of selection:-all processes spun out of the human mind, without an iota of direct evidence in their favor.

This absence of evidence drives us to the conclusion that, so far as inductive proof is concerned, natural selection now stands, not as Darwin originally proposed it (in the extreme form revived by Weismann), but as Darwin left it in his later judgment, namely, as the arbiter of fitness in groups, species, varieties, individuals, and in single characters when they are of sufficient importance to weigh in the scale of survival.

When, however, we turn to Spencer as the champion of Lamarckism, we find him open to precisely the same criticism : he discusses probabilities rather than facts. This is partly because in the very broad field of science and philosophy which he has attempted to cover-so broad that in the present advanced state of knowledge one must sacrifice depth to breadth in the attempt-he has not kept pace with the progress of biology. His standpoint is exactly similar to that of his Principles of Biology published many years ago, and of his more recent essay Factors of Organic Evolution. This pardonable unfamiliarity with recent work is the apparent cause of his failure to give his attack upon Weismann the inductive basis, which was within his reach; but more than this it has led him to a statement of his position which is absolutely fatal to his whole case and which Weismann has surprisingly overlooked. It occurs in the conclusion of his first article :

"See, then, how the case stands. Natural selection, or survival of the fittest, is almost exclusively operative throughout the vegetal world and throughout the lower animal world, characterized by relative passivity. But with the ascent to higher types of animals, its effects are in increasing degrees involved with those produced by inheritance of acquired characters; until, in anımals of complex structures, inheritance of acquired characters becomes an important, if not the chief, cause of evolution."

Now the reverse of this principle is established by the researches of recent embryology ; for, as the physical and mechanical basis of inheritance has now proved to be the same from the lowest to the highest organisms, the transmission of acquired characters must either extend from the lowest to the highest, or, as Weismann believes, it must diminish from the lowest to the highest. When Spencer says that this transmission increases towards the highest organisms he is not only 
wrong in his facts but he cedes the case to Weismann, for adaptations in plants and in lower organisms are precisely the same in kind as those in the higher and the law of heredity must be the same.

The weakness in Spencer's attack on evolution by selection exclusively is further seen in his failure to take advantage of the evidence afforded by palæontology and by human anatomy that the fundamental postulate of the selectionists that adaptive structures arise out of the fortuitous play of adaptive and non-adaptive variations is negatived by direct evidence to the contrary. Palæontology shows conclusively that there is an adaptive trend in variation under the operation of some law; whether this is the Lamarckian law or some unknown law remains to be determined.

This discussion, at least in its theoretical phase, has reached its climax in this controversy. It must now enter the new phase of test by induction. Theoretically the subject is talked out, and Spencer and Weismann render their chief service in showing that ingenuity and logic on the two sides can be so evenly arrayed against each other. It is evident to the few biologists who have been able to keep cool in this heated period that we must now suspend speculation and turn to the more exact methods of science. The reaction towards the inductive tests of the problem is already well under way.

Columbia College.

HENRY F. OSBORN.

\section{HYSTERIA, ALTERNATING PERSONALITY, PARAM- NESIA, THOUGHT-TRANSFERENCE.}

Histoire d'une Idée Fixe. PIERRE Janet. Revue Philosophique, xxxviI. 121-168. Feb. 1894 .

In this article Janet gives another of his monographic studies of the 'hysteric' condition. The patient was a woman of forty, of psychopathic heredity, who from early childhood had had fears and spasmodic attacks, and who, at the age of $x 7$, in consequence of having assisted at the 'laying out' of two cholera patients, was seized with a haunting fear of this disease, which in three years made of her a wreck. Her worst feature consisted in frequent convulsive attacks of dread of the cholera, with vomiting, purging, and hallucinations of every sense. This condition had already lasted twenty years when Janet first saw the patient. The treatment consisted first in altering, by suggestions made during the attacks, now one and then another element of the terrifying hallucinations, until their whole character was changed. This cured the attacks; but the original state of waking choleraphobia returned. 